\title{
CONHECIMENTO EM EMPRESAS DE PEQUENA DIMENSÃO NO SETOR DE CONSTRUÇÃO CIVIL
}

\author{
KNOWLEDGE IN SMALL COMPANIES IN \\ CONSTRUCTION SECTOR
}

\author{
Hilka Pelizza Vier Machadoa \\ Giane Shirley da Silvab \\ Flávio Bortolozzic
}

\begin{abstract}
RESUMO
Introdução: A gestão do conhecimento é um campo que vem sendo aplicado em empresas de pequena dimensão. Objetivo: Esta pesquisa teve como objetivo identificar formas de criação, compartilhamento e armazenamento do conhecimento por empresas de pequena dimensão do setor da construção civil. Metodologia: Realizou-se um estudo qualitativo, com estudos de casos múltiplos, junto a cinco empresas de pequena dimensão. Os dados foram coletados por meio de entrevistas semiestruturadas junto a empreendedores, engenheiros e mestres de obras, totalizando dez entrevistas. Para a análise dos dados foi realizada codificação e categorização. Resultados: Os resultados mostram que o conhecimento é obtido de fontes externas formais e informais e de fontes internas, sendo esta última principalmente o diário de obras. O compartilhamento ocorre de modo formal e de modo informal. O armazenamento é viabilizado por softwares, planilhas, relatórios e arquivos no Dropbox. Conclusão: Os resultados mostraram que as empresas utilizam pouco as fontes internas para criação do conhecimento e que compartilham as informações principalmente em reuniões.
\end{abstract}

Descritores: Informação. Gestão do Conhecimento. Construção Civil. Empresa de Pequena Dimensão.

a Doutorado em Engenharia de Produção pela Universidade Federal de Santa Catarina (UFSC). Professor do Mestrado em Gestão do conhecimento do Centro Universitário UniCesumar e pesquisadora do ICETI Instituto Cesumar de Ciência, Tecnologia e Inovação. E-mail: hilkavier@yahoo.com

b Mestre em Gestão do Conhecimento pela UniCesumar. E-mail: gianeshirley@hotmail.com

c Engenharia de Computação pela Université de Technologie de Compiègne. Professor do Mestrado em Gestão do Conhecimento da UniCesumar. Pesquisador do ICETI - Instituto Cesumar de Ciência, Tecnologia e inovação. E-mail: flavio.bortolozzi.53@gmail.com 


\section{INTRODUÇÃO}

Toda organização, independentemente do seu tamanho, tem uma rede de informações que pode ser acessada para melhorar seu desempenho e para capacitar pessoas (CARVALHO, 2012). A maximização da utilização dessas informações depende da capacidade das empresas de se organizarem e se estruturarem. Nesse sentido, a gestão do conhecimento é um campo de estudos que contribui para que as empresas possam transformar informações em conhecimento.

Empresas orientadas para o conhecimento utilizam o conhecimento como recurso estratégico, contam com processos de gestão do conhecimento, exploram informações internas e externas e utilizam tecnologias de informação para valorização do conhecimento (ALYA, 2012). Para estas empresas, o escopo do conhecimento pode ser direcionado para o conhecimento incremental, para melhoria ou para inovação radical (BASKERVILE; DULEPOVICI, 2006).

Tradicionalmente aplicado a grandes organizações, a gestão do conhecimento vem sendo considerada relevante também para empresas de pequena dimensão (WEE; CHUA, 2013; DURST; EDVARDSSON, 2012), na medida em que o conhecimento é um recurso estratégico para a criação de valor e pode contribuir para a sobrevivência e crescimento das empresas (JULIEN, 2010; TERRA; KRUGLIANSAS, 2003). Por meio do conhecimento, empresas de pequena dimensão podem se tornar mais competitivas e inovar (OLIVEIRA; EPAMINONDAS, 2014).

Um dos setores que concentra empresas de pequena dimensão no Brasil é o da construção civil (SINDUSCON, 2014). No Estado do Paraná, local onde esta pesquisa foi realizada, este setor tem uma importância para o fortalecimento da economia, sendo o que mais oferece emprego (CBIC, 2014). $\mathrm{Na}$ construção civil, as empresas tendem a especializar as atividades e a promover a aproximação das operações por meio de um trabalho coordenado. A falta de transferência de conhecimento pode prejudicar o desempenho final, ocasionando retrabalho ou repetição de erros. Além disso, a rotatividade de 
pessoas, resultante do término de projetos, contribui para que informações e conhecimentos gerados acabem sendo perdidos ou arquivados (MARTINS, 2013; MEDEIROS, 2012).

Esse setor tem recebido incentivos do governo brasileiro, mas é ainda conservador, tradicional e pouco inovador (SHREIBER; PINHEIRO, 2016). Ele é conhecido pelo atraso nos procedimentos gerenciais e em técnicas construtivas, como também pela mão de obra desqualificada, resultando em baixos índices de produtividade, atrasos nos prazos de entrega, não conformidade e baixa qualidade do produto (FREJ; ALENCAR, 2010).

A gestão do conhecimento pode contribuir para aumentar a capacidade de inovação, especialmente para empresas de pequeno porte que não dispõem, na maioria das vezes, de tecnologia necessárias, na medida em que esta requer elevados investimentos (JULIEN, 2010).

Estudos anteriores abordaram a gestão de conhecimento em empresas de pequena dimensão (DURST; EDVARDSSON, 2012; EVANGELISTA; et al., 2014; TRINDADE; et al., 2016; WEE; CHUA, 2013), mas poucos focaram a empresa de pequena dimensão no setor de construção civil. Para Wee e Chua (2013) é necessário que estudos foquem o conhecimento na empresa de pequeno porte em diferentes contextos e setores. Nesse sentido, Natale, Neves e Carvalho (2016) analisaram a gestão do conhecimento em uma empresa do setor da construção civil, mas focaram nas percepções dos gerentes em uma empresa de médio porte.

Considerando a relevância do setor da construção civil, bem como a necessidade de compreender o conhecimento em empresas de pequena dimensão em contextos específicos, esta pesquisa teve como objetivo identificar formas de criação, compartilhamento e armazenamento de conhecimento por empresas de pequena dimensão do setor da construção civil. Para consecução do objetivo foi realizado um estudo qualitativo, por meio de estudos de casos múltiplos, junto a cinco empresas de pequena dimensão no setor da construção civil.

Este artigo está organizado em quatro partes, além desta introdução. Inicialmente apresenta-se uma revisão da literatura, abordando o conhecimento 
em empresas de pequena dimensão. Em seguida, foram apresentados os procedimentos utilizados para a pesquisa de campo, bem como os resultados, seguido da análise e de considerações finais.

\section{CONHECIMENTO EM EMPRESAS DE PEQUENA DIMENSÃO}

O conhecimento é importante para a gestão de organizações, pois ele alimenta o processo de tomada de decisão e o planejamento (CHOO, 2003; TARAPANOFF, 2006). Contudo, ele precisa estar ao alcance de todos, a todo o momento e em qualquer etapa dos processos, na medida em que ele não é exclusivo (JULIEN, 2010).

Gutiérrez (2006) distingue seis tipos de conhecimento em uma organização, sendo:

a) conhecimento tácito e conhecimento explícito. O tácito é baseado na experiência pessoal e, em muitos casos, identifica- se com as habilidades do indivíduo. Sua principal característica é ser de difícil comunicação e transmissão, não sendo acessível de forma direta a outros indivíduos.

O conhecimento explícito, por sua vez, caracteriza-se pelo fato de poder ser codificado diretamente em um sistema de representação como na linguagem natural, por exemplo. Neste sentido, é facilmente transmissível ou comunicável, sendo, portanto, de acesso direto para outros indivíduos (GUTIÉRREZ, 2006, p. 123).

b) conhecimento individual e conhecimento organizacional ou corporativo. $\mathrm{O}$ individual refere-se a todo conhecimento uma pessoa possui na organização, abrangendo os seus conhecimentos tácitos e explícitos. As habilidades individuais, os contatos $e$ as relações pessoais ou os conhecimentos técnicos de uma pessoa podem ser identificados como parte desse conhecimento individual. Por sua vez, conhecimento organizacional ou corporativo é aquele que se pode atribuir a uma organização. Esse conhecimento costuma estar representado em algum tipo de documento ou em bases de dados da organização ou ainda sob a forma de propriedade intelectual e de patentes. 
c) conhecimento interno / conhecimento externo. Conhecimento interno é considerado crítico para o funcionamento de uma organização, sem o qual o funcionamento da organização seria impossível. O conhecimento externo é aquele utilizado por uma organização para relacionar-se com outras organizações. O conhecimento contido nos informes publicados sobre a organização ou aquilo que ele disponibiliza na Internet são exemplos desse tipo de conhecimento.

A gestão do conhecimento representa um conjunto de atividades com a finalidade de orientar a criação, armazenamento e compartilhamento do conhecimento (ANGELONI, 2008). Para este fim, as empresas utilizam-se de fontes internas e externas e do conhecimento dos indivíduos (NGUYEN, 2011) e o conhecimento pode ocorrer de forma deliberada ou focada (BASKERVILE; DULEPOVICI, 2006). A produção do conhecimento em organizações pode ser analisada como um ciclo da gestão do conhecimento, como mostra a Figura 1.

A primeira fase do ciclo é representada pela criação de conhecimento. Ela é dependente de gerenciamento e organização dos fluxos e das fontes de informação, pois o funcionamento da organização resulta da informação transformada, que coordena e orienta os recursos (JULIEN, 2010). A criação do conhecimento é representada pelo desenvolvimento de novas ideias resultantes da interação entre as pessoas (WEE; CHUA, 2013). Para Dalkir (2011), a codificação do que é relevante é importante para a criação do conhecimento. Baskervile e Dulepovici (2006) consideram que a criação do conhecimento pode ocorrer de forma individual ou em equipe e os procedimentos podem ser por tentativa e erro ou pela heurística.

A próxima etapa do ciclo é a avaliação, que leva em consideração o valor do conhecimento para as especificidades do usuário. Como resultado da avaliação, as pessoas compartilham o conhecimento criado e o disseminam na organização. A confiança é um elemento importante para o compartilhamento (WEE; CHUA, 2013), que pode ocorrer de modo formal ou informal (BASKERVILE; DULEPOVICI, 2006).

O ciclo tem a contextualização como etapa final, sendo o conhecimento incorporado aos processos da organização (DALKIR, 2011). Posteriormente, o 
conhecimento pode ser armazenado na memória, tanto de forma tácita como de forma articulada para posterior reutilização (BASKERVILE; DULEPOVICI, 2006).

Figura 1 - Ciclo Integrado da Gestão do Conhecimento

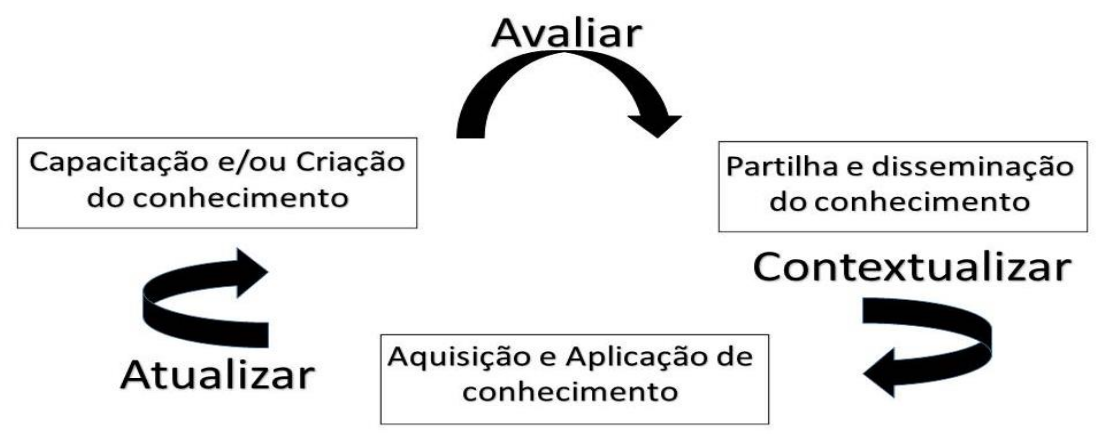

Fonte: Dalkir (2011, p. 78).

A implantação do processo de gestão do conhecimento em empresas de pequena dimensão pode impactar no desempenho econômico e financeiro dessas empresas, gerando efeitos sobre a lucratividade, sobre o crescimento de vendas e redução de custos. Efeitos sobre o desempenho do mercado podem resultar em aumento da fatia de mercado, qualidade do serviço, flexibilidade do mercado, melhoria da reputação da empresa, satisfação do cliente e melhoria de serviços aos clientes. $O$ desempenho técnico da empresa pode ser melhorado com a implantação da gestão do conhecimento, por meio da geração de inovação, da melhoria da qualidade do produto, do aumento da competência central e de flexibilidade técnica. Outros efeitos sobre 0 desempenho humano, tais como criatividade, satisfação e iniciativa foram observados em estudos anteriores. Além disso, o desempenho da empresa pode melhorar em decorrência de parcerias e relacionamentos e por meio da difusão de novas ideias, contribuindo para agilidade organizacional, para melhoria das relações de trabalho e para constante melhoria da curva de aprendizado (CERCHIONE; ESPOSITO; SPADARO, 2015).

Como vantagem, a implantação da gestão do conhecimento em pequenas empresas conta com a simplicidade da estrutura interna (WEE, CHUA, 2013). Desouza e Awazu (2006) mencionam que empresas de pequena 
dimensão são espaços de socialização do conhecimento, em razão da proximidade entre os membros e da dinâmica de funcionamento. A internalização do conhecimento ocorre por meio da comunicação entre o proprietário e os funcionários, muitas vezes de modo informal. O proprietário, em geral, tem uma função central nos processos de conhecimento na empresa de pequena dimensão (DESOUZA; AWAZU, 2006; DURST; EDVARDSSON, 2012).

Em razão disso, a capacidade de absorver informações e de gerar conhecimentos em empresas de pequena dimensão está diretamente associada ao nível educacional do empreendedor e de seus funcionários, assim como à experiência de todos. Nesse sentido, estratégias como o treinamento de funcionários, são importantes para estimular a geração de conhecimento na empresa de pequena dimensão (LEE; WONG, 2015). Não apenas o empreendedor e os funcionários, mas também clientes, parceiros e fornecedores são fontes de ideias (CERCHIONE; ESPOSITO; SPADARO, 2015). Empresas de pequena dimensão podem utilizar ideias de clientes, por meio de mídias sociais, transformando-os de recebedores passivos a ativos contribuintes de inovações (CHUA; BANERJEE, 2013).

Além disso, um recurso que empresas de pequena dimensão utilizam com frequência para obter e compartilhar conhecimento são as redes ou networks (BALESTRIN; VERSCHOORE, 2010; EVANGELISTA; ESPOSITIO; LAURO; RAFA, 2010). Por meio delas, empreendedores podem construir parcerias que resultem na criação e no compartilhamento do conhecimento (WEE; CHUA, 2013). Wee e Chua (2013) constataram ainda que o conhecimento em empresas de pequena dimensão é compartilhado por meio de reuniões.

Para armazenamento do conhecimento, estratégias de empresas de pequena dimensão incluem a utilização de repositórios (LEE; WONG, 2015), banco de ideias (STANKOWITZ et al., 2015) e, principalmente aplicativos nas nuvens, tais como Googledocs, entre outros (WEE, CHUA, 2013). Elas utilizam ainda e-mails, boletins e podcastings, vídeo conferências e mídia social para armazenar conhecimento (CERCHIONE et al., 2015). Outros recursos 
tecnológicos utilizados por empresas são: Facebook, Twitter, Foursquare (CHUA; BANERJEE, 2013). Nesse sentido, a tecnologia é importante para o armazenamento do conhecimento (NGUYEN, 2011). Ademais, entre as ferramentas de gestão do conhecimento que empresas de pequena dimensão utilizam para criar, armazenar e transferir conhecimentos estão: encontros informais, comunidades de compartilhamento, comunidades virtuais, redes informais, equipes de projetos, rotação de atividades e treinamento (CERCHIONE; ESPOSITO; SPADARO, 2015).

Contudo, em geral, empresas de pequena dimensão encontram dificuldades para obtenção de informações porque seus recursos são limitados e os custos são elevados (JULIEN, 2010), o que contribui para que elas utilizem o conhecimento tácito com maior intensidade do que as grandes empresas (DURST; EDVARDSSON, 2012). Barreiras culturais interferem na transferência e no compartilhamento de conhecimento, além de barreiras financeiras, associadas ao investimento necessário, que é alocado em outras prioridades. Outras barreiras incluem a falta de uma linguagem compartilhada, falta de confiança nos benefícios, falta de suporte gerencial, falta de habilidades e competências, falta de tempo, assim como barreiras tecnológicas (CERCHIONE; ESPOSITO, SPADARO, 2015). Além disso, a informalidade da empresa de pequena dimensão dificulta a codificação do conhecimento, que é predominantemente tácito e não formalizado. Outra barreira mencionada por Cerchione, Esposito e Spadaro (2015) é a proteção da informação crítica, que impede o compartilhamento na empresa de pequena dimensão.

Wong e Aspinval (2005) mencionam fatores críticos para o sucesso de um programa de gestão do conhecimento em empresas de pequena dimensão. Primeiramente, eles consideram que o êxito de um programa depende de uma liderança e suporte, sendo o empreendedor o que normalmente se encarrega desta tarefa. Outro fator é a existência de uma cultura que valorize o conhecimento e, aliado a este, a tecnologia de informação é importante recurso. Os autores consideram ainda que a empresa de pequena dimensão precisa delinear estratégias voltadas ao conhecimento e ter um sistema de mensuração e infraestrutura organizacional, com processos e atividades 
delineadas de modo a favorecer a incorporação de conhecimentos. Segundo os autores, uma política de recursos humanos, que motive, treine, eduque e valorize o conhecimento na organização é outro fator de sucesso. Nesse sentido, a valorização de empregados antigos pode contribuir para 0 conhecimento na empresa de pequena dimensão (JULIEN et al., 2009).

\section{PROCEDIMENTOS METODOLÓGICOS}

Esta pesquisa é um estudo qualitativo e exploratório. A pesquisa qualitativa fundamenta-se na perspectiva de interpretação dos indivíduos, focando em um conjunto de práticas interpretativas que são transformadas em várias representações como observações, anotações, gravações e documentos (FLICK, 2009; SAMPIERI; COLLADO; LUCIO, 2013).

O método da pesquisa foi o estudo de casos, utilizado para compreensão de fenômenos organizacionais. Nesta pesquisa o tipo de estudos de casos foi o de casos múltiplos, por representarem maior validade (YIN, 2015). Foram realizados estudos em cinco empresas de pequena dimensão do setor da construção civil, todas localizadas no mesmo município. Foram consideradas empresas de pequena dimensão empresas com menos do que 100 empregados, seguindo critério sugerido por Cressy (2009).

A escolha das empresas foi realizada por acessibilidade e pelo critério bola de neve, em que os participantes iniciantes indicaram novos participantes de sua rede. Como critério de validade e confiabilidade, para cada caso, foi construído um protocolo, composto por quatro seções detalhando: uma visão geral do estudo de caso, procedimentos para coleta de dados; questões para a coleta de dados e relatório constando o público da pesquisa, conforme sugere Yin (2015).

Dados primários foram obtidos por meio de entrevistas semiestruturadas, seguindo roteiro com as seguintes questões abertas sobre a dinâmica de criação, compartilhamento e armazenamento de conhecimento: como a empresa busca informações? Quais as fontes de informação que empresa utiliza? Como a empresa analisa informações que obtêm e as 
incorpora às atividades da empresa? Como o conhecimento é compartilhado na empresa? Após ser utilizado, como o conhecimento é protegido e arquivado na empresa?

Os sujeitos da pesquisa foram os proprietários e fundadores das empresas, bem como mestres de obras e engenheiros. Com isso, procurou-se atender o critério de triangulação. O Quadro 1 apresenta informações sobre os sujeitos da pesquisa e duração das entrevistas.

Quadro1 - Sujeitos da Pesquisa e Duração das Entrevistas.

\begin{tabular}{|c|l|r|}
\hline CASO & Sujeitos da Pesquisa & $\begin{array}{c}\text { Duração } \\
\text { das entrevistas }\end{array}$ \\
\hline A & EA1- Engenheiro Responsável & 45 minutos \\
& EA2 - Sócio Proprietário & 30 minutos \\
\hline B & EB1- Engenheiro Proprietário & 45 minutos \\
& EB2- Mestre de obras & 30 minutos \\
\hline C & EC1- Mestre de obras & 40 minutos \\
& EC2- Engenheiro Proprietário & 60 minutos \\
\hline D & ED1- Engenheiro Proprietário & 30 minutos \\
\hline E & ED2- Engenheiro Responsável & 60 minutos \\
& EE1- Engenheiro Proprietário & 30 minutos \\
\hline
\end{tabular}

Fonte: Elaborado pelos autores

As entrevistas foram transcritas na íntegra, totalizando 400 minutos e 67 páginas. Após a transcrição, o material foi enviado por e-mail aos respondentes, como critério de validação dos dados.

Em seguida, o material das entrevistas foi codificado, como sugerem Bauer e Gaskell (2008). Para categorização levou-se em consideração a validade semântica, a validade da amostra (conteúdo representativo dos participantes de cada caso) e a validade do constructo, ou seja, a teoria subjacente sobre conhecimento em empresas de pequena dimensão. As categorias resultantes da codificação foram: criação, compartilhamento e armazenamento do conhecimento. 


\section{APRESENTAÇÃO E ANÁLISE DOS DADOS}

As empresas de construção civil, de acordo com Fontenelle (2002) são divididas em: a) edificações: ligadas às residências, comércio e serviços complementares; b) construção pesada: infraestrutura urbana, industrial, barragem, saneamento, dentre outras; c) montagem industrial: estruturas para instalação de indústria, sistemas para distribuição de energia, telecomunicações e recursos naturais. Nesta pesquisa, as empresas enquadram-se, na maioria, como edificações, sendo empresas pequenas, também denominadas construtoras. Em algumas construtoras identificou-se a estratégia da criação de subempreiteiras de mão-de-obra, destinadas ao desenvolvimento dos serviços de estrutura e execução do serviço. As empresas que fizeram parte deste estudo utilizam subcontratação para realização de suas atividades.

\subsection{Perfil das Empresas}

A empresa A foi criada em abril de 1996, pelo engenheiro proprietário. Atualmente ela conta com vinte funcionários, incluindo temporários. A estrutura é composta por dois setores, sendo o administrativo responsável por contratos de terceiros, filtragem de informações sobre a obra e assuntos gerais de administração; e o setor de engenharia, responsável pela organização dos projetos e execução de obras. A principal mudança na trajetória da empresa ocorreu no ano de 2000, quando ela começou a participar de processos de licitação de obras públicas.

A empresa B foi criada em novembro de 2013 por dois engenheiros. Eles terceirizam toda a mão de obra, contando com aproximadamente 14 terceirizados. A principal mudança na empresa consistiu na decisão de atuar em projetos de arquitetura e na ênfase em capacitação de desenhos.

A empresa C iniciou as atividades em dezembro de 2012 pelo engenheiro proprietário. Ela é voltada a projetos arquitetônicos, de engenharia e execução de obras. A estrutura da empresa está dividida em setores: 
administrativo, de engenharia e desenho arquitetônico. Conta com 10 funcionários fixos e terceiriza o serviço de execução de obras, quando necessário. A principal estratégia, que marcou o desenvolvimento da empresa, foi focar na execução de obras, estudando aos poucos a implementação de ações.

A empresa D foi aberta em março de 1997, por dois sócios engenheiros, atuando no ramo de Arquitetura e construção para médio porte. Internamente, a empresa conta com 15 funcionários, distribuídos nos setores administrativos, de engenharia e arquitetura, e de obras. De acordo com a necessidade, eles terceirizam o trabalho de execução. A principal transformação na empresa foi a mudança no foco de mercado, voltado para empresas de grande porte.

As atividades da empresa E tiveram início em agosto de 2008, com os dois engenheiros proprietários. $\mathrm{O}$ momento principal ocorreu quando resolveram mudar para o segmento de terraplanagem. Ela conta com 23 funcionários, que estão alocados em setores administrativos e de engenharia.

\subsection{Criação de Conhecimento}

Para buscar informações externas e transformá-las em conhecimento a empresa A adota a estratégia de participação em Feiras do Setor, assim como a realização de assinaturas de revistas especializadas e eventos promovidos pelo Conselho Regional de Engenharia, além de pesquisa na internet. Além disso, ela conta com fornecedores e clientes para obter informações.

A empresa B obtém informações em cursos promovidos pelo Conselho Regional de Engenharia, em assinatura de revistas especializadas e fica atenta às novidades na internet. Além disso, ela busca ideias em conversas informais com fornecedores. As informações são analisadas e registradas em computadores da empresa.

Na empresa C, a participação em palestras em universidades, sindicatos e órgãos do setor, como também leitura de revistas especializadas e participação em cursos cadastrados na Associação Brasileira de Consultores de Engenharia (ABCE), constituem as principais fontes de informações. Essa 
empresa utiliza também consultorias. As informações obtidas são transportadas em planilhas no Excel e no aplicativo Trello. A proteção da informação ocorre por meio de arquivos no Dropbox. Os projetos e planejamentos de execução de obras são realizados e registrados no sistema BIM (Bulding Information Modeling), utilizado para modelagem de informações em 3D.

No caso da empresa $D$, a busca por informações ocorre por meio de participação em Feiras Nacionais e Internacionais do setor, assim como pela participação em palestras e simpósios. Ela utiliza ainda informações fornecidas pela Associação Comercial do Município, bem como assinatura de revistas especializadas. Outra modalidade para obtenção de informações por essa empresa são consultorias que ela contrata eventualmente. A transformação das informações em conhecimento ocorre por meio do sistema Sienge, um gerenciador de projetos, utilizado para planejar, programar e representar graficamente as informações. Além disso, o Project é um software que a empresa utiliza para realizar o acompanhamento de cada etapa do serviço.

A empresa $E$ busca as informações por meio da participação em Feiras e em Associações de Negócios. A pesquisa na internet ocorre com frequência, a fim de identificar novidades do mercado. A empresa utiliza redes sociais como fonte de informação e ressaltou a utilização do diário de obras como fonte de informações interna. Para organizar as informações e planejar as atividades a empresa conta com suporte dos softwares Sienge e Project. $\mathrm{O}$ Quadro 2 apresenta um resumo das fontes de informação utilizadas pelas empresas para criação do conhecimento. 
Quadro 2 - Fontes de informação para a criação do conhecimento por empresas de pequena dimensão da construção civil

\begin{tabular}{|l|l|}
\hline CASO & Formas de criação do conhecimento \\
\hline A & $\begin{array}{l}\text { Fornecedores e clientes. } \\
\text { Participação em Feiras } \\
\text { Assinatura de Revistas Especializadas } \\
\text { Consulta a sites na Internet }\end{array}$ \\
\hline B & $\begin{array}{l}\text { Participação em Cursos } \\
\text { Assinatura de Revistas Especializadas } \\
\text { Consulta a sites na Internet } \\
\text { Contato e informações obtidas junto a fornecedores }\end{array}$ \\
\hline C & $\begin{array}{l}\text { Consulta a sites na Internet } \\
\text { Participação em palestras em Universidades e Sindicatos } \\
\text { Assinatura de Revistas Especializadas } \\
\text { Contratação de consultores } \\
\text { Participação em Redes Sociais }\end{array}$ \\
\hline D & $\begin{array}{l}\text { Participação em Feiras } \\
\text { Palestras promovidas pela Associação dos engenheiros. } \\
\text { Contratação de consultoria } \\
\text { Assinatura de Revistas Especializadas }\end{array}$ \\
\hline \multirow{5}{*}{ E } & $\begin{array}{l}\text { Participação em Associações de Negócios } \\
\text { Participação em Feiras } \\
\text { Acesso a sites na Internet } \\
\text { Participação em Redes Sociais } \\
\text { Utilização de Diário de Obras }\end{array}$ \\
\hline
\end{tabular}

Fonte: Elaborado pelos autores

Além destes aspectos, considerando os casos em conjunto, observou-se que a experiência de mestres de obras e de engenheiros representa uma fonte de conhecimentos para as empresas. Em um dos casos desta pesquisa 0 mestre de obra contava com 37 anos de experiência no setor, tendo sido enfatizada a importância da participação dele durante as reuniões, como uma fonte de conhecimento relevante. Trata-se de conhecimento individual de acordo com a classificação de Tarapanof (2006), que pode se transformar em conhecimento organizacional. 


\subsection{Compartilhamento e Armazenamento de Conhecimento}

Medeiros e Melhado (2013) ressaltam a importância, nas empresas de construção civil, do compartilhamento do conhecimento de projetos entre as equipes para melhorar o desempenho e para minimizar estruturas e processos ineficientes. Nesta pesquisa o compartilhamento do conhecimento ocorre principalmente entre as equipes de obras.

$\mathrm{Na}$ empresa $\mathrm{A}$, reuniões semanais são os principais mecanismos para compartilhar conhecimento. Durante as reuniões os participantes analisam registros constantes no diário de obras, sendo a informação compartilhada entre todos os profissionais de cada área. Nesses eventos eles compartilham erros, possíveis soluções, produzindo um aprendizado em conjunto. Medeiros e Melhado (2013, p. 13) identificaram que a transferência de conhecimento ocorre entre as fases do projeto, sendo que a interação ocorre entre projetista, construtora, clientes e fornecedores. Eles também identificaram interações em reuniões de acompanhamento de projetos: "o contato face a face em reuniões para desenvolvimento e resolução de problemas de projeto foram identificados como melhores canais de comunicação para compartilhar conhecimentos relacionados ao processo de projeto, tanto para equipes de gestão, projeto e obra."

$\mathrm{Na}$ empresa B, o compartilhamento do conhecimento ocorre na comunicação entre engenheiro e mestre de obras, tendo por base os registros no diário de obras. Em reuniões semanais com os funcionários são transmitidas informações, sendo também realizado o planejamento de obras.

A empresa $C$ compartilha o conhecimento por meio de documento (circular) com informações sobre obras. Os integrantes da empresa também realizam reuniões periódicas. Redes sociais, e-mails, telefones e conversas informais são formas de circular o conhecimento e as informações entre funcionários, clientes e fornecedores. Além disso, ela utiliza o software Trello para compartilhamento de informações.

$\mathrm{Na}$ empresa $\mathrm{D}$, reuniões semanais têm por finalidade promover $\mathrm{o}$ compartilhamento do conhecimento, utilizando como fonte de informações, 
principalmente, relatórios e diário de obras. Com os clientes, os proprietários realizam reuniões quinzenais.

$\mathrm{Na}$ empresa $\mathrm{E}$, reuniões semanais com os encarregados promovem discussões e compartilhamento de conhecimento, sendo o foco principal o prazo e custos das obras. Com funcionários, são realizadas reuniões quinzenais. A interação e o compartilhamento ocorrem entre funcionários, engenheiros e encarregados. Com os clientes, a empresa troca informações e conhecimentos por meio de relatórios quinzenais, compartilhando internamente por e-mail e externamente de forma verbal.

É importante ressaltar o papel das reuniões no compartilhamento do conhecimento. Esses momentos são focos de análise, discussão e filtragem de informações. A ênfase recai sobre o planejamento de obras, bem como sobre o acompanhamento da execução, como pode ser observado nos seguintes trechos:

$\mathrm{Na}$ reunião a gente faz o planejamento de equipe, para onde vai cada equipe, por exemplo, a gente tem seis ou sete equipes na empresa hoje, cada uma vai para um lugar (EE1).

Toda semana a gente faz uma reunião semanal, normalmente na segunda-feira ou às vezes na sexta, para traçar uma diretriz para a próxima semana, para fechar como foi a semana, para gente ver os erros e partir para a próxima semana assim, tentando solucionar tudo, deixando em ordem (EA1).

Geralmente a gente tenta compartilhar esse conhecimento na nossa reunião de sexta-feira e nas nossas reuniões mensais com os mestres de obras. A gente sempre está passando o conhecimento para o pessoal, alguma coisa que a gente deu uma lida e viu que dá para melhorar um pouco, sempre está tentando passar (ED1).

Tal como Desouza e Awazu (2006) e Wee e Chua (2013) constataram que empresas de pequena dimensão são espaços de socialização do conhecimento, em razão da proximidade entre os membros e da dinâmica de funcionamento, nas empresas de construção civil que participaram desta pesquisa o compartilhamento ocorre de forma interativa e pessoal, por meio de comunicação entre os proprietários e os funcionários. Mas, diferente do que constataram Durst e Edvardsson (2012) sobre a centralidade do proprietário 
nos processos de conhecimento da empresa de pequena dimensão, nesta pesquisa a centralidade dos proprietários é compartilhada com engenheiros e mestres de obras, principalmente os que contam com experiência.

Além disso, observou-se algumas formas de cooperação e de interação entre empresas e clientes, voltadas ao desenvolvimento dos projetos e serviços em conjunto, gerando conhecimento em nível Inter organizacional, tal como foi encontrado por Larentis et al. (2014). Nas empresas pesquisadas, o conhecimento é compartilhado de maneira explícita entre fornecedores e clientes. Esta estratégia de conhecimento junto a clientes e fornecedores é importante para a empresa de pequena dimensão gerar conhecimento (LEE; WONG, 2015), embora, de acordo com os dados, as empresas explorem pouco essa fonte de informação.

Sobre o armazenamento do conhecimento, a empresa A utiliza softwares e o diário de obras como fonte de armazenamento. A empresa $B$ utiliza a intranet. $\mathrm{Na}$ empresa $\mathrm{C}$, relatórios são utilizados para armazenar informações, além de dropbox e sistema BIM para registro de obras. O registro de informações e conhecimentos na empresa $D$ ocorre por meio de e-mails, que registram também informações sobre fornecedores e clientes. Esta empresa utiliza os softwares Sienge e Project para armazenar dados de projetos e obras. Na empresa $\mathrm{E}$, as informações são registradas em planilhas, protegidas em forma de backups. O conhecimento de obras e de projetos é registrado nos sistemas Sienge e Project.

Quanto ao armazenamento, de modo geral, as empresas enfatizaram o armazenamento de informações relativas a projetos e execução, com pouca ênfase a informações de clientes e de mercado, o que poderia trazer informações sobre oportunidades de mercado (EVANGELISTA; et al., 2010). Medeiros e Melhado (2013) identificaram a utilização de sistemas de informação para armazenar documentos, como projetos, desenhos e especificações manuais em empresas de construção civil. Nas empresas que participaram desta pesquisa esse registro ocorre em softwares específicos, tais como o Sienge e o Project. O Quadro 3 apresenta uma síntese das formas 
utilizadas pelas empresas para criação, compartilhamento e armazenamento de conhecimentos.

Quadro 3 - Criação, compartilhamento e armazenamento do conhecimento por empresas de pequena dimensão do setor da construção civil

\begin{tabular}{|c|c|c|c|}
\hline CASO & Criação & Compartilhamento & Armazenamento \\
\hline A & $\begin{array}{l}\text { Fornecedores e } \\
\text { clientes. } \\
\text { Feiras. } \\
\text { Revistas } \\
\text { Especializadas. } \\
\text { Internet. }\end{array}$ & $\begin{array}{l}\text { Reuniões semanais. } \\
\text { Diário de obras. }\end{array}$ & $\begin{array}{l}\text { Diário de obras. } \\
\text { Softwares. }\end{array}$ \\
\hline B & $\begin{array}{l}\text { Cursos. } \\
\text { Revistas } \\
\text { Especializadas. } \\
\text { Internet. } \\
\text { Fornecedores. }\end{array}$ & $\begin{array}{l}\text { Comunicação } \\
\text { pessoal entre } \\
\text { engenheiros e } \\
\text { mestres de obras. } \\
\text { Diário de Obras. } \\
\text { Reuniões. }\end{array}$ & Internet. \\
\hline C & $\begin{array}{l}\text { Internet. } \\
\text { Palestras em } \\
\text { Universidades e } \\
\text { Sindicatos. } \\
\text { Revistas } \\
\text { Especializadas. } \\
\text { Consultores. } \\
\text { Redes Sociais. }\end{array}$ & $\begin{array}{l}\text { Circular e relatórios. } \\
\text { Diário de Obras. } \\
\text { Reuniões. } \\
\text { Redes Sociais. } \\
\text { E-mails. } \\
\text { Funcionários. } \\
\text { Clientes. } \\
\text { Fornecedores. } \\
\text { Trello. }\end{array}$ & $\begin{array}{l}\text { Relatórios. } \\
\text { Dropbox. } \\
\text { Sistema BIM. }\end{array}$ \\
\hline D & $\begin{array}{l}\text { Feiras. } \\
\text { Palestras. } \\
\text { Associações } \\
\text { dos } \\
\text { engenheiros. } \\
\text { Consultoria. } \\
\text { Revistas } \\
\text { Especializadas. }\end{array}$ & $\begin{array}{l}\text { Diário de obra. } \\
\text { Reunião com } \\
\text { clientes. } \\
\text { Relatórios. }\end{array}$ & $\begin{array}{l}\text { E-mail. } \\
\text { Sienge. } \\
\text { Project. }\end{array}$ \\
\hline$E$ & $\begin{array}{l}\text { Associações de } \\
\text { Negócios, } \\
\text { Feiras } \\
\text { Internet } \\
\text { Redes Sociais } \\
\text { Diário de Obras }\end{array}$ & $\begin{array}{l}\text { Reuniões. } \\
\text { Relatórios aos } \\
\text { clientes. } \\
\text { E-mail. }\end{array}$ & $\begin{array}{l}\text { Planilhas. } \\
\text { Sienge. } \\
\text { Project. } \\
\text { Diário de Obras. }\end{array}$ \\
\hline
\end{tabular}

Fonte: Elaborado pelos autores 
A comunicação, tanto a verbal como a escrita, é relevante para gerenciamento de informação e para promoção de conhecimento (DALKIR, 2011; MEDEIROS, 2012). Nesta pesquisa, a comunicação verbal ocorre, predominantemente, em reuniões com a equipe interna e às vezes com clientes. A comunicação escrita foi observada por meio de relatórios e planilhas e com destaque ao diário de obras, principal instrumento utilizado no compartilhamento de informações e conhecimento pelas empresas nesta pesquisa. Além disso, a empresa C utiliza o software Trello para compartilhamento de informações e conhecimento.

Com base no ciclo do conhecimento de Dalkir (2011), o conhecimento nas empresas desta pesquisa caracteriza-se como mostra a Figura 2. Inicialmente, quanto às fontes de busca de conhecimento constatou-se que as empresas buscam o conhecimento por meio de:

a) Fontes Externas, tendo sido identificadas fontes impessoais e pessoais. Como fontes impessoais foram mencionadas: sites de internet, revistas especializadas, cursos, palestras e feiras. Fontes pessoais identificadas foram: contatos com fornecedores e clientes, consultores, bem como participação em redes (Associação de Engenheiros e outras redes sociais). Ideias de clientes e fornecedores são fontes de conhecimento para pequenas empresas, o que também foi constatado por Cerchione, Esposito e Spadaro (2015).

b) Fontes internas, tendo sido citado apenas o diário de obras. Este resultado mostra como as empresas utilizam pouco as fontes internas de conhecimento. Apenas a empresa C mencionou o conhecimento de funcionários, mas somente durante a etapa do compartilhamento. Para Julien et al. (2009), funcionários mais antigos representam uma fonte importante para aumentar a capacidade de absorção do conhecimento.

Estes resultados mostram que as empresas utilizam mais fontes impessoais e que o processo de busca está organizado na figura do empreendedor, tal como mencionado por Durst e Edvardsson (2012). Os dados da pesquisa mostraram ainda que as empresas formalizam pouco 0 conhecimento obtido. Nesse sentido, a implantação de banco de ideias, pode 
constituir um mecanismo inicial formalizar o conhecimento (STANKOWITZ et al., 2015). Outra estratégia pode ser o registro de boas práticas e, como Medeiros e Melhado (2013, p. 19) salientam: "boas práticas devem ser compartilhadas com equipes internas e com parceiros externos (projetistas, fornecedores, consultores)."

Sobre o compartilhamento do conhecimento, a segunda etapa do ciclo do conhecimento, esta é, segundo Desouza e Awazu (2006), a fase mais crítica do ciclo. Nas empresas pesquisadas o compartilhamento ocorre de modo:

a) Formal: com a utilização de circular, relatórios, software Trello, emails e diário de obras.

b) Informal: reuniões, redes sociais, conversas com funcionários, clientes e fornecedores e reuniões com clientes.

Entre os recursos utilizados para compartilhamento, as reuniões foram mencionadas em estudos anteriores (DESOUZA; AWAZU, 2006; LEE; WONG, 2015; WEE; CHUA, 2013).

$\mathrm{Na}$ última etapa do ciclo do conhecimento, a do armazenamento, as empresas utilizam os softwares Sienge, Project, Excel para manutenção e guarda do conhecimento. Além disso, o conhecimento é registrado em planilhas, relatórios e essencialmente no diário de obras. Para arquivamento as empresas utilizam o Dropbox. 
Figura 2 - Ciclo do conhecimento em empresas de pequena dimensão da construção civil

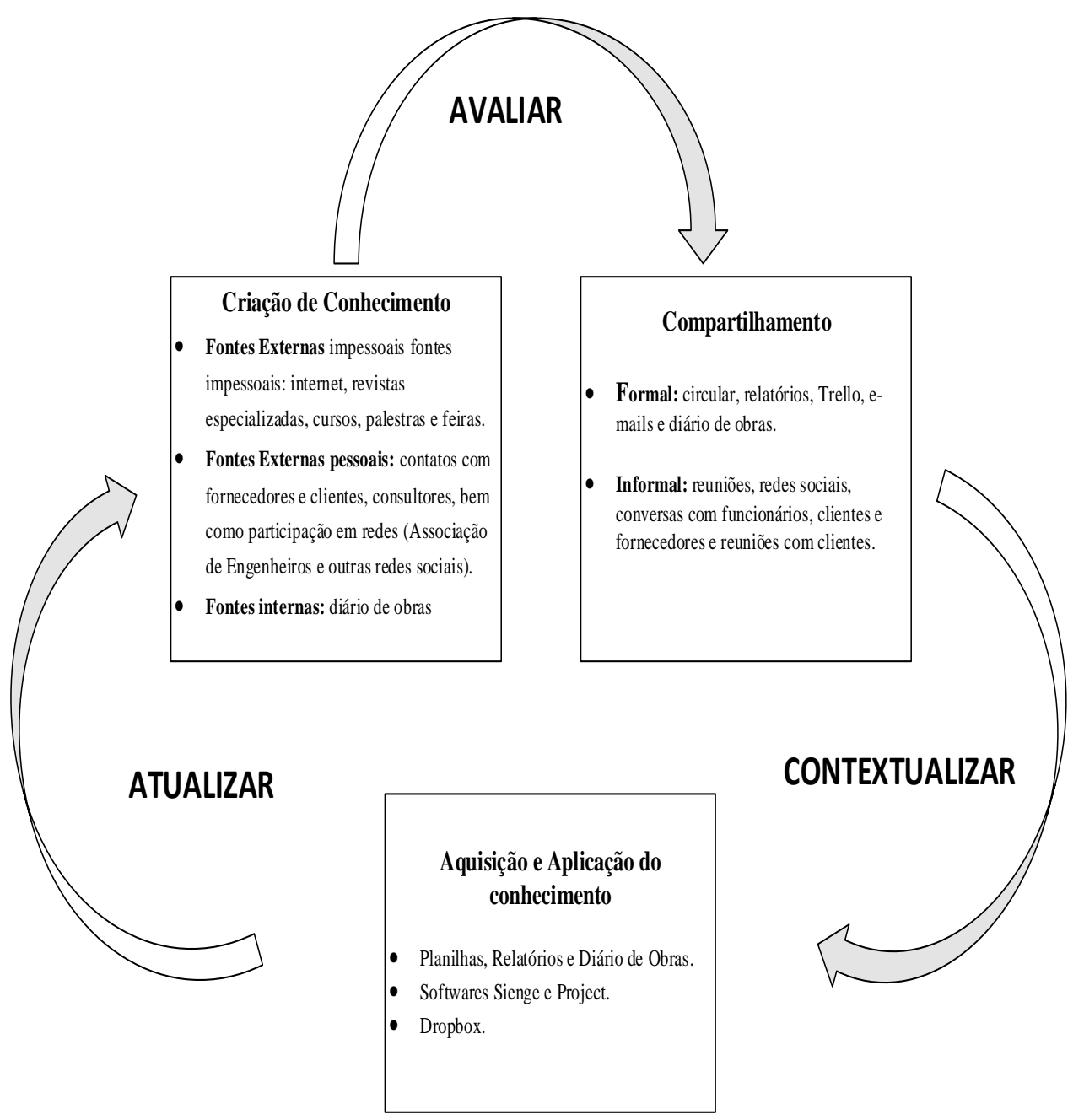

Fonte: Elaborado pelos autores com base em Dalkir (2011).

Os resultados desta pesquisa reforçam a afirmação que o conhecimento tácito e a socialização são inerentes à dinâmica de negócios de pequena dimensão, como apontaram Durst e Edwardsson (2012) e Desouza e Awazu (2006).

Ainda que essas práticas tenham sido identificadas nessas empresas de pequena dimensão do setor da construção civil, o conhecimento não integra as estratégias e a cultura delas, sendo que elas priorizam a informação técnica, de modo diferente do encontrado por Ziviani, Ferreira e Silva (2015), que constataram que o conhecimento e aprendizagem estavam integrados em 
processos e na cultura de organizações como parte integrante da estratégia empresarial.

\section{CONSIDERAÇÕES FINAIS}

A gestão do conhecimento é relevante para empresas do setor de construção civil, pois estas, em geral, gerenciam múltiplos projetos (FREJ; ALENCAR, 2010). Ademais, a criação e a aplicação do conhecimento constituem um caminho para inovação em empresas de pequena dimensão no setor da construção civil (SCHREIBER; PINHEIRO, 2016).

Esta pesquisa teve como objetivo identificar formas de criação, compartilhamento e armazenamento de conhecimento por empresas de pequena dimensão do setor da construção civil. Os resultados mostraram que o conhecimento é obtido a partir de fontes externas, formais e informais e de fontes internas, sendo esta última principalmente o diário de obras. Além disso, o compartilhamento do conhecimento nas empresas ocorre de modo formal e de modo informal. Quanto ao armazenamento da informação e do conhecimento, este é viabilizado com a utilização de softwares, planilhas, relatórios e arquivos no Dropbox.

De acordo com os resultados desta pesquisa as principais fontes de informações utilizadas pelas empresas para a criação do conhecimento foram revistas especializadas, Feiras e sites da internet. Duas empresas mencionaram ainda informações obtidas em redes sociais, bem como junto a consultores e fornecedores. Como principais formas de compartilhamento do conhecimento utilizadas pelas empresas destacam-se as reuniões e o diário de obras. Uma das empresas compartilha também informações com clientes, por meio de relatórios. Tanto nas formas de criação, como de compartilhamento, é importante que o conhecimento seja incorporado aos processos da organização, como sugere Dalkir (2011), a fim de que o conhecimento possa ser reutilizado e dinamizado no âmbito das empresas.

Esta pesquisa apresenta uma contribuição teórica ao abordar a gestão do conhecimento em um setor relevante para a economia e, além disso, em um 
setor cuja atuação é importante para geração de inovação, sendo o conhecimento relevante neste contexto. A limitação do estudo deve-se ao fato de todos os casos serem da mesma localidade e as empresas do mesmo tipo de construção civil (execução).

A dinâmica do conhecimento nesse setor pode ser mais bem compreendida por meio de pesquisas futuras que abordem o conhecimento em grandes empresas desse setor, bem como em pesquisas que foquem a utilização e reutilização do conhecimento nessas empresas.

\section{REFERÊNCIAS}

ALYA, C. L'Organisation fondée sur le savoir : caracteristiques et utilité théorique et pratique. 2012. $272 \mathrm{f}$. Thèse (Doctorat Sciences de Gestion) Université de Toulouse, 2012.

ANGELONI, M. T. Organização do conhecimento: infraestrutura, pessoas e tecnologia. 2. ed. São Paulo: Saraiva, 2008.

BALESTRIN, A.; VERSCHOORE, J. A aprendizagem e inovação no contexto das redes de cooperação entre pequenas e médias empresas. Organização \& Sociedade, Salvador, v. 17, n. 53, p. 311-330, 2010.

BASKERVILLE, R.; DULIPOVICI, A. The theoretical foundations of knowledge management. Knowledge Management Research \& Practice, v. 4, p. 83-105, 2006.

BAUER, M. W.; GASKELL, G. Pesquisa qualitativa com texto: imagem e som: um manual prático. Petrópolis: Vozes, 2008.

CARVALHO, F. C. A. Gestão do Conhecimento. São Paulo: Pearson, 2012.

CERCHIONE, R.; ESPOSITO, E.; SPADARO, M. R. The Spread of Knowledge Management in SMEs: A Scenario in Evolution. Sustainability, v. 7, p. 1021010232, 2015.

CÂMARA BRASILEIRA DA INDÚSTRIA DA CONSTRUÇÃO (CBIC). 2014.

Disponível em: <http:// www.cbic.org.br>. Acesso em: 18 dez. 2014.

$\mathrm{CHOO}, \mathrm{C}$. W. A organização do conhecimento: como as organizações usam a informação para criar significado, construir conhecimento e tomar decisões. São Paulo: Editora SENAC, 2003. 
CHUA, A. Y. K. BANERJEE, S. Customer knowledge management via social media: the case of Starbucks. Journal of Knowledge Management, v. 17, $\mathrm{n}$. 2, p. 237-249, 2013.

CRESSY, R. Determinants of Small Firm Survival and Growth. In: CASSON, M. $\mathrm{N}$. The Oxford Handbook of entrepreneurship. New York: Oxford University Press, 2009. p. 161-193.

DALKIR, K. Knowledge Management in Theory and Practice. Burlington: Elsevier, 2011.

DESOUZA, K., C. AWAZU, Y. Knowledge management at SMEs: five peculiarities. Journal of Knowledge Management, v. 10, p. 32-43, 2006.

DURST, S.; EDVARDSSON, R. Knowledge management in SMEs: a literature review. Journal of Knowledge Management, v. 16, n. 6, p. 879-903, 2012.

EVANGELISTA, P.; et al. The Adoption of Knowledge Management Systems in Small Firms. Electronic Journal of Knowledge Management, v. 8, n. 1, p. 3342, 2010.

FONTENELLE, E. C. Estudo de Caso sobre a Gestão de Projetos em Empresas de Incorporação e Construção. 2002. 383 f. Dissertação (Mestrado em Engenharia) - Universidade de São Paulo, Escola Politécnica, São Paulo, 2002.

FLICK, U. Qualidade na Pesquisa Qualitativa. Porto Alegre: ARTMED, 2009.

FREJ, T. A.; ALENCAR, L. H. Fatores de sucesso no gerenciamento de múltiplos projetos na construção civil em Recife. Produção, v. 20, n. 3, p. 322334, 2010.

JULIEN, P. A.; et al. La capacité d'absorption, l'élément clé dans la compréhension de la relation entre information et innovation Le cas des PME du Congo-Brazzaville. Revue Internationale P. M. E., v. 22, n. 2, 2009.

JULIEN, P. A. Empreendedorismo Regional e economia do conhecimento. São Paulo: Saraiva, 2010.

LARENTIS, F. et al. Aprendizagem organizacional e relacionamentos interorganizacionais: Um estudo de caso múltiplos. Revista de Administração e Contabilidade da Unisinos, v. 11, n. 4, p. 347-366, 2014.

LEE, C. S.; WONG, Y. Development and validation of knowledge management performance. Journal of Knowledge Management, v. 19, n. 4,p. 711-734, 2015. 
MARTINS, V. W. B. Análise do desenvolvimento de competências gerenciais na construção civil através do modelo da aprendizagem baseada em problemas adaptado ao contexto organizacional. 2013. $92 \mathrm{f}$. Dissertação (Mestrado em Engenharia Civil) - Universidade Federal do Pará, Instituto de Tecnologia, Belém, 2013.

MEDEIROS, M. C. I. Gestão do Conhecimento Aplicada ao processo de projeto na construção civil: Estudo de caso em construtoras. 2012. $418 \mathrm{f}$. Dissertação (Mestrado em Engenharia) - Universidade de São Paulo, Escola Politécnica, São Paulo, 2012.

MEDEIROS, M. C. I., MELHADO, S. S. Gestão do conhecimento aplicada ao processo de projeto na construção civil: estudos de caso em construtoras. Boletim Técnico da Escola Politécnica da USP, EPUSP, 2013. 24 p.

NATALE, C. H. C.; NEVES, J. T. R.; CARVALHO, R. B. de. Maturidade em Gestão do Conhecimento: Análises das percepções dos gestores de uma grande empresa de construção civil. Informação \& Informação, Londrina, v. 21, n. 1, p. 375-406, jan./abr. 2016.

NGUYEN, T. H. H. Knowledge Management in Small and Medium sized Enterprise (SME), developing country Vietnam. 2011. $179 \mathrm{f}$. Thesis (Doctorate in Economics and Management) - Tomas Bata University, Zein. 2011.

OLIVEIRA, P. H.; EPAMINONDAS, M. E. R. Conhecimento, Inovação e Estratégia competitiva: um estudo no setor atacadista da moda. Revista Eletrônica de Estratégia e Negócios, v. 7, n. 1, p. 83-104, 2014.

SAMPIERI, R. H.; COLLADO, C. F.; LUCIO, M. P. B. Metodologia de Pesquisa. Porto Alegre: Penso, 2013.

SCHREIBER, D.; PINHEIRO, I. A. Análise das práticas de inovação em construção civil. Contextus, v. 14, n. 2, p. 6-35, 2016.

SINDICATO DA INDÚSTRIA DA CONSTRUÇÃO CIVIL (SINDUSCON). Programa Inovação tecnológica. 2014. Disponível em: <http://www.sindusconrio.com.br>. Acesso em: 01 de agosto de 2014.

STANKOWITZ, R. F. et al. Gestão de Ideias na pequena e média empresa. In: Congresso Latino-lbero americano de Gestão da Tecnologia, 16, 2015. Anais eletrônicos... Porto Alegre: ALTEC: 2015.

GUTIÉRREZ, M. Pérez-Montoro. O Conhecimento e sua Gestão em Organizações. In: TARAPANOFF, K. Inteligência, Informação e Conhecimento em corporações. Brasília: IBICT, UNESCO, 2006. 456 p. 
TERRA, J. C; KRUGLIANSKAS, I. Gestão do Conhecimento em Pequenas e Médias Empresas. Rio de Janeiro: Campus, 2003.

TRINDADE. E. P. et al. Soluções de Gestão do Conhecimento para Pequenas e Médias Empresas. Perspectivas em Gestão \& Conhecimento, v. 6, p. 189203, 2016.

YIN, R. K. Estudo caso: Planejamento de Métodos. 5. ed. Porto Alegre: Bookman, 2015.

WEE, J. C. N.; CHUA, A. Y. K. The peculiarities of knowledge management processes in SMEs: the case of Singapore. Journal of Knowledge Management, v. 17, n. 6, p. 958-972, 2013.

WONG, K. Y.; ASPINVAL, E. An empirical study of the important factors for knowledge management adoption in the SMEs. Journal of Knowledge Management, v. 9, n. 3, p. 64-82, 2005.

ZIVIANI, F.; FERREIRA, M. A. T.; SILVA, S. M. da. Avaliação da Maturidade em Gestão do Conhecimento em Organizações Mineiras. Revista Eletrônica de Estratégia \& Negócios, Florianópolis, v. 8, n. 1, p. 240-263, 2015.

\title{
KNOWLEDGE IN SMALL COMPANIES IN CONSTRUCTION SECTOR
}

\begin{abstract}
Introduction: Knowledge management is a field that has been applied in small companies. Objective: The aim of this research was to understand forms of creation share and keep information in knowledge by companies with small dimension in the Construction Industry. Methodology: A qualitative study was developed with studies of multiple cases, in five companies. The data were collected through semi structured interviews with entrepreneurs, engineers and employees, a total of ten interviews. Results: The results show that those companies look for information in formal and informal external sources, as well as in internal sources. The storage is possible with softwares, reports and files in Dropbox. Conclusions: The results showed that the companies use little the internal sources for creation of the knowledge and that they share the information mainly in meetings.
\end{abstract}

Descriptors: Information. Knowledge Management. Construction Sector. Small Business.

\section{CONOCIMIENTO EN EMPRESAS DE PEQUEÑA DIMENSIÓN EN EL SECTOR DE CONSTRUCCIÓN CIVIL}

Inf. Inf., Londrina, v. 23, n. 2, p. 493 - 519, maio/ago. 2018.

http://www.uel.br/revistas/informacao/ 


\section{RESUMEN}

Introducción: La gestión del conocimiento es un campo que viene siendo aplicado en empresas de pequeña dimensión. Objetivo: Esta búsqueda tuvo como objetivo identificar formas de creación, compartir y almacenar el conocimiento por empresas de pequena dimensión del sector de la construcción civil. Metodología: Realizou-se un estudio cualitativo, con estudios de casos múltiples, junto a cinco empresas de pequena dimensión. Los datos se recogieron por medio de entrevistas semiestruturadas junto a los emprendedores, los ingenieros y los maestros de obras, totalizando diez entrevistas. Resultados: Los resultados muestran que el conocimiento es obtido de fuentes externas formais y la información de fuentes internas, siendo esta última principalmente el diário de obras. El uso ocorre de modo informal y formal. O almacenamiento de datos por medio de softwares, planilhas, documentos y archivos no Dropbox. Conclusiones: Los resultados muestran que las empresas utilizan poco las fuentes internas para la creación de conocimiento y que comparten información principalmente en reuniones.

Descriptores: Información. Gestión del Conocimiento; Construcción Civil. Empresas de Pequeña dimensión.

Recebido: 10.03. 2017

Aceito: 27.02 .2018

Inf. Inf., Londrina, v. 23, n. 2, p. 493 - 519, maio/ago. 2018

http://www.uel.br/revistas/informacao/ 